\title{
An Appraisal of Gender Mainstreaming in Census of India 2011
}

\author{
Mohmad Saleem Jahangir, Aneesa Shafi \\ Department of Sociology, University of Kashmir, Srinagar, India \\ Email: saleemjehangir@gmail.com
}

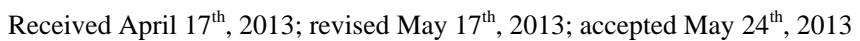

\begin{abstract}
Copyright (c) 2013 Mohmad Saleem Jahangir, Aneesa Shafi. This is an open access article distributed under the Creative Commons Attribution License, which permits unrestricted use, distribution, and reproduction in any medium, provided the original work is properly cited.
\end{abstract}

\begin{abstract}
Population census is a total process of collecting, compiling, evaluating, analyzing and publishing demographic, economic and social data pertaining, at a specified time, to all persons in a country or in a well defined part of a country, drawing valid conclusions in situations of uncertainty and variability. Usually in the context of prevailing gender discrimination issues, the figures revealed by means of census also have divulged gender bias. Taking notice of this, efforts were made to make Census of India 2011 gender sensitive in order to reveal a gender sensitive and objective picture of Indian population. The present paper aims to understand and evaluate the whole activity of Census of India 2011 as a tool ensuring gender mainstreaming.
\end{abstract}

Keywords: Census; Gender; Fertility; Migration; India; Household; Enumeration

\section{Introduction}

Population Census is one of the fundamental tasks of the government of any state. It has become a backdrop for government's political, economic and social policy formation. It is a mechanism the government used to levy taxes, military service, apportion representation and communal labour. Population census is one of the key planning strategies towards sustainable development and progress of a nation. It provides answer to "How many we are" in terms of the total number of people living in the entire nation, "Who we are?" in terms of age, sex, education, occupation, economic activity and other crucial characteristics, as well as "Where we live" in terms of housing and access to social amenities. The answers to these questions will provide numerical profile for planning and development within a nation by providing, expanding and sustaining the infrastructures that will enhance the quality of life of the people (United Nations, 2008).

A population census is a principal means of collecting basic population statistics as a part of an integrated programme of data collection and compilation aimed at providing a comprehensive source of statistical information for economic and social development planning, for administrative purposes, and for research and other uses. The value of census is increased if the results can be employed together with the results of other investigations, and if it can furnish the information needed for conducting other statistical investigations. The use of consistent concepts and definitions throughout an integrated programme is essential if the advantages of the relationships between population census and other statistical investigations are to be fully realized (United Nations, 1980).

In country like India, with multiethnic, multilingual, multicultural and multilevel society, the census is more than a mere head count of the population. It gives a snapshot of not only the demographic but also the economic, social and cultural profile of the country at a particular point of time. More often than not, it is the only available source of primary data at the level of village and town (ward).

The Indian Census has a rich tradition and enjoys the reputation of being one of the best in the world. The first census in India was conducted in the year 1872 but was conducted at different points of time in different parts of the country. In 1881 a census was taken for the entire country simultaneously. Since then, Census has been conducted every ten years, without a break. Thus, the Census of India 2011 is the $15^{\text {th }}$ in the unbroken series since 1872 (RGI, 2010).

\section{Census of India 2011}

Census of India 2011 marks a milestone in the history of Census. It has been undertaken at a time when India is at an inflexion point in history, when it sheds the legacy of the past and emerged among the comity of Nations as a strong, selfreliant and modern Nation. The basic benchmark statistics on the state of human resources, demography, culture and economic structure at this crucial juncture of the country's history would be vital to guide and shape the future of the Nations (Chandramouli, 2011: p. 2).

The Census of India 2011 was conducted in two phases, viz. "House-listing and Housing Census" and "Population Enumaration". During the first phase of Census, census houses and households were identified and systematically listed in the House-listing and Housing Census Schedule during the period April to September 2010 all across India. Apart from listing houses, some useful data on the amenities available to the households were also collected for assessing condition of human settlement and housing deficits. During the second phase of the census, the population of India was enumerated taking into consideration various socio-economic, demographic and other variables into account. The enumeration period was fixed from February 09 to 28, 2011 with a revisional round of March 01 to 05,2011 . During this enumeration period entire popula- 
tion living in households was enumerated and on the night of February 28, 2011, the houseless population was enumerated. The census moment and the reference date for the Census of India 2011 is 00.00 hours of March 01, 2011. In order to update the population with reference to the census moment, enumeration of new visitor(s)/household(s) had to be undertaken who, otherwise, were not enumerated earlier and also the birth(s) were taken into account those who got birth after the household was enumerated but before the census moment. Also the entries were cancelled in the household schedules of those persons who died after the enumeration but before census moment. Births, deaths and arrivals of visitors that took place after 00.00 hours of March 01, 2011 were not considered for enumeration.

\section{Persons Enumerated}

All households were covered to enumerate the entire population without omission and duplication, however taking care of the following four rules:

1) All those who normally resided and were present in that household during the entire period of enumeration i.e. from February 09 to 28, 2011 (including both the days);

2) Also those who are known to be normally residing and had actually stayed during a part of the enumeration period in the household (February 09 to 28, 2011) but are not present at the time of being enumerated.

3) Also those who were known to be normally residing in the household and were not present at the time of enumeration but were expected to return by February 28, 2011; and

4) Visitors who were present in the household enumerated and were expected to be away from the place of their normal residence during the entire enumeration period. For the purpose of enumeration such visitors were treated as normal residents of the households where they were actually found during the enumeration period provided they were not enumerated elsewhere.

The above four regulations clearly reveal that nationality was not the criterion for enumeration i.e. anyone who was foreign national but could qualify for any of these regulations was enumerated. However, the foreigners and their families who were having diplomatic status were not enumerated although the Indian nationals employed and staying with them were enumerated.

\section{Census Variables}

The census of India is conducted once in a decade, following an extended de facto canvasser method. Under this approach, data is collected from every individual by visiting the household and canvassing the same questionnaire all over the country. Census of India 2011 focused on eleven variables. These are Sex, Age, Marital Status, Religion, Caste and Tribe, Disability, Language, Literacy, Work, Migration and Fertility. The household schedule enquired of these variables in form of following 29 heads (RGI, 2010):

1) Name of the person;

2) Relationship with head;

3) Sex (Male, female or Other);

4) Date of Birth and Age;

5) Current Marital Status (never married, currently married, widowed, separated or divorced); Age at Marriage;

6) Religion;

7) Schedule Caste/Schedule Tribe;

8) Disability (Disability in Seeing, Hearing, in Speech, in movement, Mental retardation, Mental illness, any other or multiple Disabilities);

9) Mother Tongue; Other languages Known;

10) Literacy Status (illiterate or literate); Status of attendance (attending School, College, Vocational, Special Institution for disabled, literacy centre, any other institution, attended before or never attended); Highest educational level attained;

11) Work Particulars: Worked any time last year (main worker, marginal worker or non-worker); Category of Economy activity (Cultivator, Agricultural Labourer, Worker in household industry or other worker); Characteristics of Workers and Non Workers-Occupation; Nature of Industry, trade or service; Class of Worker (Employer, Employee. Single Worker, Family Worker); Non-Economic Activity (for non workers and marginal workers); Seeking or available for work (for non workers and marginal workers); Travel to place of work (for other workers);

12) Birth Place;

13) Migration Characteristics: Place of Last residence within or outside India and place of last residence at the time of migration (rural or urban); Reason of Migration (Work/employment, Education, Marriage, Moved after birth, moved with household or any other); Duration of stay in this village/town since migration;

14) Fertility Particulars: Children surviving; Children ever born; Number of children born alive during last one year.

\section{Gender Mainstreaming}

Gender remains one of the most prominent axis of exclusion. As Jo Bealle avers, gender is an essential construct within which, questions regarding the processes and outcomes of marginalization in the urban environment must be framed. She argues that “... women and men are not just workers or homemakers but have a range of social roles in the household, market and community. If the concept of gender helps to uncover the constructed, and thus mutable, nature of these social roles, it also directs attention to the interaction between the organization of work and other social relationships. The consequence of this interaction for many women is a burden of multiple responsibilities for both social reproduction and economic production, many of which are unremunerated and thus invisible in national accounts and other data used for planning purposes” (Bell, 1996).

Population enumeration by gender composition is one of the indispensable demographic characteristics and provides significant demographic scrutiny. Census of India has the practice of bringing out information by gender composition on various aspects of the population. Changes in gender composition largely reflect the underlying social, economic and cultural patterns of the society in different ways.

According to the Nobel Laureate Amartya Sen, we have seven types of gender disparities. However, the disparity between women and men can take many different forms. Indeed, gender disparity is not one homogeneous phenomenon, but a collection of disparate and interlinked problems. In some regions in the world, disparity between women and men directly involves matters of life and death, and takes the brutal form of unusually high mortality rates of women and a consequent preponderance of men in the total population, as opposed to the preponderance of women found in societies with little or no gender bias in health care and nutrition (Sen, 2001). 
Given a preference for boys over girls that many societies, belonging particularly to India, have gender bias can manifest itself in the form of the parents wanting the newborn to be a boy rather than a girl. Even when demographic characteristics do not show much or any male bias, there are other ways in which women can have less than a square deal. Girls have far less opportunity of schooling than boys do. There are other deficiencies in basic facilities available to women, varying from encouragement to cultivate one's natural talents to fair participation in rewarding social functions of the community. Even when there is relatively little difference in basic facilities including schooling, the opportunities of higher education may be far fewer for young women than for young men. In terms of employment as well as promotion in work and occupation, women often face greater handicap than men. In many societies the ownership of property can also be very unequal. Even basic assets such as homes and land may be very asymmetrically shared. The absence of claims to property can not only reduce the voice of women, but also make it harder for women to enter and flourish in commercial, economic and even some social activities. There are often enough, basic inequalities in gender relations within the family or the household, which can take many different forms. Even in cases in which there are no overt signs of male bias in, say, survival or son preference or education, or even in promotion to higher executive positions, the family arrangements can be quite unequal in terms of sharing the burden of housework and child care.

Once we have an overview of Indian society vis-à-vis its culture, one could easily find trace the cultural roots of this prevailing gender bias. The issues of women ranging from Sati to Widow Remarriage have historically pushed the women to the back foot. Such issues could also be found in the census related activities also.

Even though gender had been a prominent cross-cutting priority in 2001 census, data related to female count, marital status, female headed households, female disability and female workparticipation has continued to suffer from under count or under reporting. The 2001 census enumerated several villages/districts that had reported very few women, very low female literacy and no female worker. To ensure an accurate picture an attempt to integrate gender issues into the various stages of the census taking has been undertaken and briefly described in this note.

Firstly, gender critical areas were identified on basis of three criteria emerging from the 2001 Census. These were: overall sex ratio, female literacy and female work participation. The advantages of using these three indicators are that they reflect the status of the women and additionally enable analysis at the lowest disaggregated level, i.e. village level. Thus, districts with low sex ratio (less than 900); low female literacy (less than $30 \%$ ) or low female work participation rate (less than 20\%) were identified on the basis of 2001 Census. Likewise analysis with a different cut-off was done for cities/towns and 262 gender-critical districts (including cities/towns) out of the 593 districts across the country were identified for focused attention. The number of gender critical districts have been identified in Uttar Pradesh (60), followed by Bihar (28), Haryana (18), Orissa (17), Punjab (16), Madhya Pradesh (16), Rajasthan (15), Assam (12), Delhi (9), Jammu \& Kashmir (8), Kerala (9), Jharkhand (8), Arunachal Pradesh (7), Gujarat (4), Nagaland (3), Tripura (3), West Bengal (3), Uttaranchal (3), Maharashtra (3), Puducherry (3), Mizoram (2), Tamil Nadu (2), Himachal
Pradesh (1), Andra Pradesh (1), Karnataka (1) and Chandigarh (1) (Census of India 2001).

Enumerator training in these 262 districts was considered the key to ensuring completeness and accuracy of data concerning women and girls. Hence, for these 260 gender critical districts, it was been decided to create a pool of 260 Gender Master Trainer Facilitators (GMTFs) for training of enumerators in the specific gender module (instead of Master Trainers), thus minimizing the diffusion losses due to the cascade approach of training and covering about 1.2 million enumerators.

It was decided that the key gender elements will be integrated throughout the generic training module that explains how to ask and fill up information for each question in the schedule. This was also complemented by the development of a gender-specific module for the identified 260 critical districts only. This ensured that gender aspects were mainstreamed across the training module to be used in all districts and additional attention will be given through the specific gender module to the 260 districts where returns on gender parameters were not fully accurate.

The outline for generic and specific modules, training aides and kits to be developed were subsequently finalized, along with consistent gender-sensitive communication materials to reinforce gender elements and complement training efforts through publicity and communication initiatives.

Lastly, the training guides that include a specific gender module right from enumerator to national trainer levels were developed. The training guides integrate the seven categories of gender-specific issues stated above through well laid out session-plans. To facilitate the sessions, appropriate teaching aids in the form of an e-module, role-plays, quizzes, flyers and dataposters have all been developed. A two sided flyer in A4 size containing gender-data on one side and gender mainstreaming matrix on the other for 260 critical districts is being printed by RGI in local language for all the 2.7 million enumerators across the country. The flyer will form part of both generic and specific training programmes.

For reinforcing gender elements in 260 gender critical districts, bi-lingual gender-data posters (English and Hindi) were printed for use during training programmes and publicizing at training venues and government offices in the district. The GMTFs during training of enumerators discussed the district situation in 2001 census in terms of the indicators shown in the poster and later emphasize the importance of completeness of data concerning women \& girls. This was done through a 45 minute training capsule that focused on ensuring inclusion, better netting of different categories of women and appropriate information on births of girls, female headed household etc.

\section{Gender Elements in Census of India 2011}

In order to ensure the objective and inclusive coverage of people following seven elements were taken due care:

1) Full coverage of population: It is usually found that people feel hesitation in revealing the presence of any extra-ordinary or differently-abled person belonging to their family particularly that of a widow, divorced, physically or mentally challenged, etc. which could otherwise lay a considerable influence on the issues like sex ratio, population differently-abled etc. As a result, in Census of India 2011, stress was laid to ensure inclusion of females (elderly, infants, unmarried, widowed, divorced, separated and differently-abled). It was also stressed 
to count everyone, paying attention to counting newborn and infant girls, elderly women, females with disability, single, deserted, divorced and widowed.

2) Female Headed Households: The head of household for census purpose is a person who bears the chief responsibility for managing the affairs of the household and taken decision on behalf of the household. There may be cases where the head of household is away from the family for the entire period of enumeration and therefore is not eligible to be enumerated at the present place of enumeration. In such cases, the person on whom the responsibility of managing the affairs of household rests should be regarded as the head (RGI 2010: 36).

India, in present times, is undergoing through an intensified magnitude of migration with multi-dimensional nature which has subsequently led to a shift in its prevailing patriarchy. Increase in the number of female-headed-households has been one of the outcomes. However, the predominant mindset of patriarchy is not allowing us to demarcate an objective picture of these households. Variation across states in the incidence of female headship also is considerable. In some accounts, the higher incidence of female headship in particular states (e.g. Kerala) relates to traditions of a more elevated status of such women, where matriliny has been prevalent. Other explanations link the phenomenon to high rates of male outmigration, including working overseas, which may indicate that such female-headed households are comparatively well off, at least in material terms. The proportion of female-headed-households increases in older age groups and the majority are widowed, divorced or separated. The process through which female headship arises is important in terms of what forms of social support are available; this probably differs considerably across social groups or communities. (Institute of Development Studies, Brighton, 1995). Besides this, various issues have aroused with relation to the female headship and gender bias. Institute of Development Studies, Brighton 1995 stresses that:

"India contains one of the largest concentrations of poor people in the world and thus poverty has been an area of extensive debate, measurement and policy intervention. There remains considerable controversy over what measures of poverty and/or methods of poverty assessment are most appropriate and this is reflected in differing data and assessments. In spite of all the attention to poverty, differential experiences of poverty according to other caste and community, and the interactions of these with gender, are relatively under-analyzed. Whilst women's relationship to poverty is shaped by the wider context, there are also gender specific processes of impoverishment. Here, intra-household processes and the incidence of female headship are particularly considered."

Such emerging issues can be dealt once we know the nature and magnitude of the female-headed-households. Taking into account such issues, it was stressed in Census of India 2011 to undergo proper netting of female headed households. Efforts were made to correctly know and share definition of head of household with the respondent/family and correctly identify female headed households.

3) Age, Marriage and Religion: Age is one of the most important items of demographic data. It divulges a clear picture of the nature of the population in terms of children, youth and elderly. Once an objective picture is revealed, it becomes easy for a nation to understand the nature of development and related issues. It was attempted in census of India 2011 to involve the mothers to get the correct age of their children. It was also made mandatory not to assess the age of a person by her/his physical appearance (RGI 2010: 39 - 44).

Marital status is also one of the significant variables of Census. Also is evident that the data revealed from Census is required frequently required to develop sound policies and programmes aimed at fostering the welfare of the country and its people. This data source becomes indispensible for effective and efficient public administration besides serving the needs of planners. Once we have the reliable data related to marital status available with us, it becomes easy for us to identify the issues like late marriage, child marriage, divorce, widows, etc. Besides it also helps the planners and policy makers to realize the intensity of these problems and subsequently seek for their solution. The Census of India 2011 stressed to ensure an objective picture related to the marital status including age at marriage also.

It is not necessary that all the members in the household profess the same religion. Usually we inter-religious marriages taking place around us and even there are frequent religious conversions taking place nowadays. While seeking information, an enumerator usually presumes that the religion professed by the head of the household is the religion professed by whole family even though case may not be so. The Census of India 2011 focused more on asking this question to the members individually particularly those of women.

4) Disability: The data on disability is generally found useful for the varied purposes like helping the planners to allocate adequate resources and providing services to persons living with disabilities and their families. It also helps in taking adequate measures to provide them equal opportunities in education and employment and even to make available such infrastructure at various places like Railway stations, Bus Stands, Hospitals etc. which would be helpful for them.

If the picture revealed by census 2001 is analyzed, various doubts and come to the limelight which thereby force us to think about the non-reporting of the persons with disability particularly women. The Census of India 2001 reveals that United States of America has got more disability cases than of India. Consequently it was attempted in Census of India 2011 to enquire and probe about the presence of a physically or mentally disabled person. It was particularly stressed to probe for women and girls with disability, especially single and elderly women because often information regarding them is not shared. Enumerators were stressed to emphasize confidentiality of information. Enumerators were directed not to change the expression or sympathize or laugh when a person revealed about her/his disability or of her/his family member.

5) Mother Tongue and Other Languages: Mother tongue is the language spoken in childhood by the person's mother to the person. If the mother died in infancy, the language mainly spoken in the person's home in childhood will be the mother tongue. In case of infants and deaf mutes, the language usually spoken by their mother should be recorded as her/his mother tongue (RGI, 2010: 54). In present day societies of India we observe marriages taking place across cities, villages and even states which develop the possibility of having different mother tongue and languages known by every member of the household. Consequently in Census of India 2011, mother tongue of each household member, especially married female members was to be enquired and reported.

6) Literacy: Education as a means of advancement of capacity, well-being and opportunity is uncontested, and more so 
among females. During the last six decades since independence, there has been phenomenal development of education system in India resulting in the creation of one of the largest education systems of the world. The government and various other recognized and unrecognized institutions in our country offer endless educational, vocational and professional courses for the people irrespective of age and sex to enhance and enrich their skills. Usually the conservative people in India generally stop their female children from getting educated and many of them hide the literacy status of females even if they get educated. It was stressed, in Census of India 2011, that anybody who can read and write with understanding is considered to be literate and same was to be confirmed especially for women and girls. It was also made mandatory to probe to ensure that women attending adult literacy classes and girls attending non-formal education centers are reported as attending educational institution.

7) Female Work: Work may be defined as participation in any economically productive activity with or without participation compensation, wages or profit. Such participation may be physical and/or mental in nature. Work involves not only actual work but also includes effective supervision and direction of work. It even includes part time help or unpaid work on farm, family enterprise or in any other economy activity. And in census a person is categorized as a worker when she/he has participated in any economically productive activity (RGI, 2010: pp. 61-63).

The women labour constitutes an important segment of the labour force in India and their participation in the labour force is increasing over the years. Wage work in India, as elsewhere, in a number of sectors is sharply differentiated along sexual lines. There are only a few occupations, which are the exclusive preserve of either men or women. When men and women work in the same industry, one can find clear distinction between men's and women's work. However, women have often been classified as non-workers when it comes on to Census. This is primarily because of the existing patriarchal setup wherein the work of women is not acknowledged as a result their participation is not reported. It may be pertinent to reveal that in India, a large number of farm and non-farm activities are family based. Many male and female members of the cultivating households, irrespective of their age, work in the peak season of ploughing, sowing, harvesting and collection of farm production. Some of them, particularly women withdraw themselves from the labour force in the slack season. But not all of them are enumerated as workers during the census. Similarly, members of the household who work in the household industry intermittently and qualify to be treated as workers but majority of them are omitted as workers. Members of the household also participate in other seasonal economic activities, like gur making, gathering of firewood, leaves and collection of other wild growing forest material; women giving tuition classes or attending to the family shop; tending cattle for the production of milk. These women are likely missed as workers during enumeration. Even it was witnessed during enumeration many enumerators declare all those women as non-workers who are illiterate. To ensure inclusive enumeration, the census of India 2011 made it mandatory to make probing enquiries related to work. Whenever any person especially women inform that they did not work, never record them as non-worker straight away. Women are often engaged in unpaid but economically productive work. Recognize and identify such work correctly e.g. milching the cow and using milk for household consumption. Appropriate netting of female work in all economic activities especially for the informal sector and unpaid work was made.

8) Migration: For census purpose, Migration is considered to be the movement, which involves change of residence from one village/town to another village/town. For census purpose there are two types of migrants, viz. migrants by place of birth and migrants by place of last residence (RGI, 2010: p. 84). According to this definition one would usually understand that a major chunk of female population is a migrant, as marriage in India is usually patrilocal and it involves the change of residence of females. And it is usually seen that this idea is not taken into account by the enumerators and respondents while enumeration is taking place and as such omit the notion of their migration. Consequently, in Census of India 2011, proper care was taken to understand the nature of migration of females and stress was laid on probing and record correct birthplace and place of last residence for each member of the household, especially women. It was also stressed that in case of women, the primary reason for migration need not only be marriage only. There could be other reason also which could be same as those of men like employment or education. It was also stressed that the nature and reason of migration be noted separately because in the same household there may be cases where the reasons of migration are different for different members of the household.

9) Fertility: The questions related to fertility in the census of India 2011 were more gender sensitive as these were the questions which were asked in case of ever married women only. It was made advisable to obtain the information directly from the concerned female members of the household while taking care of the sensitivity of the gender and not offending the sentiments of the respondent. It is common experience that the birth of the daughter or son may not be reported readily if she or he is not actually surviving at the time of enumeration. In fact deaths are still high in this country. There is a chance of a number of such cases being missed unless specifically questioned about. It was stressed to sensitively probe for married daughters and estranged children who are not reported among currently surviving children. It was advised to probe to ensure that girls are reported among children ever born, even if they may not have survived and for female infants who were born but later died as they are often not reported at all.

\section{Results from Census of India 2011}

Subsequent to efforts put on to ensure gender inclusion, the Census of India 2011 revealed an encouraging picture of female headed households. Of the total 246,692,667 households, 26,884,345 were found to be female-headed i.e. 10.9 percent of total households showing a 0.5 percent increase to the figures of 2001. It may be pertinent to mention here that 10.4 households in rural areas were found to be female headed while as it was found to be 12 percent in urban areas, depicting 0.3 and 1.0 percent increase to the figures of 2001 respectively. In seven major States, the proportion of Single Member Female Headed Households is more than 20 percent e.g. Chhattisgarh (29.9 percent), Madhya Pradesh (24.9 percent), Tamil Nadu (26.1 percent), Andhra Pradesh (27.1 percent), Maharashtra (22.2 percent), Odisha (22.1 percent) and Gujarat (20.4 percent) (Chandramouli, 2011).

The Sex Ratio at global level has decline from 986 in 2001 to 984 2011. Same has been witnessed in United States of Amer- 
ica (1029 to 0125), China (944 to 926), Indonesia (1004 to 988), and Nigeria (1016 to 987) (Chandramouli, 2011: 78). Unlike, the Sex Ratio in the country which was 933 in 2001 has risen by 7 points to 940 in 2011. The increase in rural areas has been 1 point from 946 to 947 . The same in urban areas has been 26 points from 900 to 926. As per Census 2011, Jammu and Kashmir, Bihar and Gujarat showed a decline in sex ratio while 29 states showed an increase. Among the major States, Bihar, Jammu and Kashmir and Gujarat have experienced a fall in sex ratio. The decline ranged from 2 points in Gujarat to 9 points in Jammu and Kashmir. Other smaller Union Territories showing steep decline are Dadar and Nagar Haveli and Daman and Diu. Perceptible increase has been observed in the major States such as Uttar Pradesh, Rajasthan, Jharkhand, Orissa, Chhattisgarh, Madhya Pradesh, Andhra Pradesh, West Bengal, Maharashtra, Kerala, Tamil Nadu, Punjab and all other States located in the North East. (Chandramouli, 2011: 48). It may be pertinent to mention here that the States having historically low sex ratio such as Punjab, Haryana, Delhi and Chandigarh (which were designated as gender critical) have depicted a significant increase in the sex ratio as recorded in Census of India 2011.

There has been a considerable increase in the literacy rate of females as well. The effective literacy rate has gone up from $64.83 \%$ in 2001 to $74.04 \%$ in 2011 showing an increase of 9.21\%. As against 53.67 percent in 2001 it has increased to 65.46 percent in 2011 and the male-female gap in literacy rate has decreased from 21.59 in 2001 to 16.68 percent in 2011 ((Chandramouli, 2011: 102). Besides, the decadal difference (2001-2011) in literacy has been recorded more for females (11.79 percent) than males (6.88 percent) (Chandramouli, 2011: p. 117). The effective literacy rate figures for males and females are 82.14 and $65.46 \%$ respectively. Thus three-fourth of the population of aged 7 years and above is literate in the country. Four out of every five males and two out of every three females in the country are literate. The country has continued its march in improving literacy rate by recording a jump of 9.21 percent points during 2001-2011. However, efforts are still required to achieve the target of $85 \%$ set by the Planning Commission to be achieved by the year 2011-12. An extremely positive development in the present decade is that the gap of 21.59 percent points recorded between male and female literacy rates in 2001 Census has reduced to 16.68 percent points in 2011. Though the target set for the year 2011-2012 by the Planning Commission of reducing the gap to 10 percent points has not been achieved, yet the 5 percent point reduction is a welcome step in that direction.

\section{Conclusion}

Gender equality is more than a goal of itself. It is a precondition for meeting the challenges of reducing poverty, promoting sustainable development and building good governance. And the foundation of gender equality lies in the acknowledgement of the efforts put on by the women towards the societies and nation. The gender mainstreaming activity of Census of India 2011 was an effort to acknowledge the existence of females and their contribution towards their families and societies. The above mentioned results revealed from Census of India 2011 divulge an encouraging picture of the efforts put on to streamline the census activity on the basis of gender. Although the results revealed are not revolutionary, it could be considered as revolutionary step towards the gender equality and the method- ology adopted to carry out any census and the related activities.

\section{REFERENCES}

Akkerman, A. (2000). On the Leontief structure of household populations. Canadian Studies in Population, 27, 181-194.

Alho, J. (1994). Analysis of sample-based capture-recapture experiments. Journal of Official Statistics, 10, 245-256.

Anderton, D., Conaty, J., \& Pullum, T. (1983). Population estimates from longitudinal records in otherwise data-deficient settings. Demography, 20, 273-284. doi:10.2307/2061242

Arthur, W., \& Espenshade, T. (1988). Immigration policy and immigrants ages. Population and Development Review, 14, 315-326. doi:10.2307/1973574

Bell, W. (1993). Using information from demographic analysis in postenumeration survey estimation. Journal of the American Statistical Association, 88, 1106-1118. doi:10.1080/01621459.1993.10476381

Bourgeois-Pichat, J. (1971). Stable, semi-stable populations, and growth potential. Population Studies, 25, 235-254.

Bouvier, L. (1971). Estimating post-censal populations of counties. Journal of the American Institute of Planners, 37, 45-46. doi:10.1080/01944367108977354

Cai, Q. (2007). New techniques in small area population estimates by demographic characteristics. Population Research and Policy Review, 26, 203-218. doi:10.1007/s11113-007-9028-7

Carmen, A., \&Somoza, J. (1965). Survey methods, based on periodically repeated interviews, aimed at determining demographic rates. Demography, 2, 289-301. doi:10.2307/2060119

Carrier, N., \& Hobcraft, J. (1971). Demographic estimation for developing societies. London: Population Investigation Committee, London School of Economics

Chandramouli, C. (2011). Provisional population totals paper 1 of 2011 India series 1. India: Registrar General and Census Commissioner of India.

Chattopadhyay, M., Lahiri, P., Larsen, M., \& Reimnitz, J. (1999). Composite estimation of drug prevalences for sub-state areas. Survey Methodology, 25, 81-86.

Coale, A., \& Trussell, J. (1996). The development and use of demographic models. Population Studies, 50, 469-484. doi:10.1080/0032472031000149576

Eniayejuni, A. T., \& Agoyi, M. (2011). A biometrics approach to population census and national identification in Nigeria: A prerequisite for planning and development. Asian Transactions on Basic \& Applied Sciences, 1, 60-67.

Greene, E. B., \& Harrington, V. D. (1993). American population before the federal census of 1790. Baltimore: Genealogical Publishing Co., Inc.

Greenwood, V. D. (1990). The researcher's guide to American genealogy. Baltimore: Genealogical Publishing Company, Inc.

Institute of Development Studies (1995). Background report on gender issues in India: Key findings and recommendations. Brighton: University of Sussex

John, M. E. (2011). Census 2011: Governing populations and the girl child. Economic \& Political Weekly, 46, 10-12.

Registrar General and Census Commissioner of India (RGI) (2010). Instruction manual for updating of Abridged Houselist and filling up of the household schedule. India: Office of Registrar General and Census Commissioner of India, Ministry of Home Affairs, Government of India

Sen, A. (2001). Many faces of gender inequality. Frontline, 9.

United Nations (1980). Principles and recommendations for population and housing censuses. New York: UN Publications.

United Nations (2008). Principles and recommendations for population and housing censuses. New York: UN Publications.

Van Imhoff, E., Kuijsten, A. C., Hooimeijer, P., \&van Wissen, L. J. C. (1995). Household demography and household modeling. New York: Plenum Press. doi:10.1007/978-1-4757-5424-7

Zeng, Y. K., Wang, L. Z., \& D. Gu (2006). US family household momentum and dynamics: An extension and application of the ProFamy Method. Population Research and Policy Review, 25, 1-41. 
M. S. JAHANGIR, A. SHAFI

doi:10.1007/s11113-006-7034-9

Beall, J. (1996). Urban governance: Why gender matters. In UNDP gender in development monograph series, No. 1, New York: United Nations Development Programme. 